\title{
Gall stones in diverticula of the lower common bile duct
}

\author{
G. A. KUNE \\ From the Royal Melbourne Hospital, Melbourne, Australia
}

EDITORIAL SYNOPSIS A diagnostic pitfall in patients with obstructive jaundice is described.

Within the last few years the anatomy of the lower end of the common bile duct has been revised as a consequence of numerous investigations (Hughes and Kernutt, 1954; Dowdy, Waldron, and Brown, 1962; Hand, 1963; Kune, 1964).

The anatomy of this region is represented in Figure 1. The lower end of the common bile duct is intimately related to the second part of the duodenum, and its calibre narrows markedly just before it pierces the duodenum. The wall of the duct is thickened over this narrow segment.
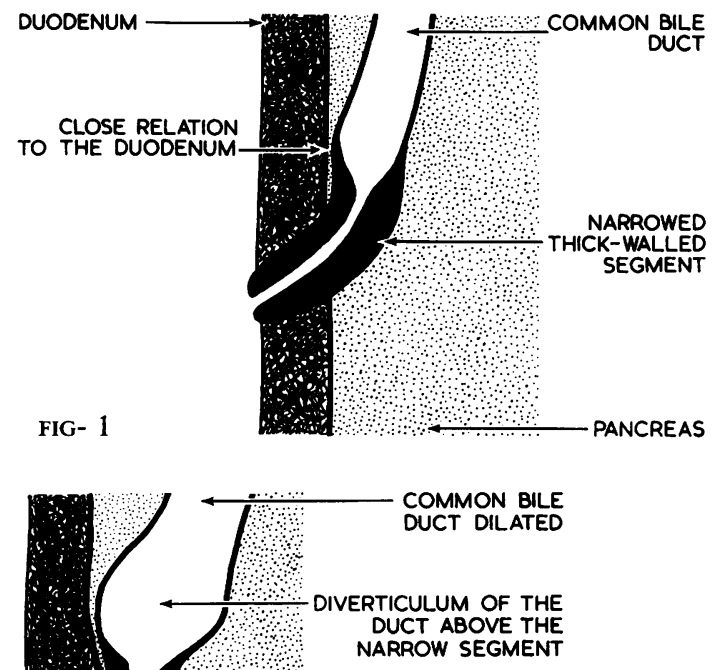

FIG. 1. A diagram of the anatomy of the lower common bile duct.

FIG. 2. A diagram of the lower end of the common bile duct under conditions of high intraductal pressure.

FIG. 2

${ }^{1}$ Present address: Lahey Clinic, 605 Commonwealth Ave., Boston, Mass., U.S.A.
When the pressure within the common bile duct is high, such as is found in cases of obstruction due to gall stones, the duct dilates and in a large proportion of cases a ballooning or diverticulum is formed. The diverticulum is very often situated on the duodenal side of the common bile duct (Kune, 1964). The lower end of the common bile duct under conditions of high intraductal pressure is shown diagrammatically in Figure 2.

Gall stones may lodge in such diverticula and are easily overlooked at operation because of their situation. Three cases are described where operative difficulties were encountered, as large stones were situated in such pouches of the lower end of the common bile duct.

\section{CASE REPORTS}

CASE 1 Mr. T. W., a 69-year-old farmer, presented with a short history of upper abdominal pain and obstructive jaundice. At operation a gall bladder containing stones was found. There was considerable oedema surounding the common bile duct. No stone was felt along the course of the duct. The common bile duct was opened and found to contain pus but no stone was found. A probe readily passed into the duodenum. Cholecystectomy was performed, and the common bile duct was closed over a $T$ tube. An operative cholangiogram was not performed.

One month after the first operation laparotomy was again performed as a post-operative cholangiogram showed a large filling defect at the lower end of the common bile duct (Fig. 3). At this operation again no stone was found. A probe readily passed into the duodenum. An operative cholangiogram was again not performed. The T tube was reinserted. A post-operative cholangiogram with the $T$ tube in position one week later once again showed the filling defect seen previously. It was decided to remove the $T$ tube and follow the patient's progress.

The patient was symptom-free for 14 months and then presented with a history of epigastric pain, vomiting, and obstructive jaundice for one month. He had lost 2 stone in weight. He was resuscitated, and a third operation was 


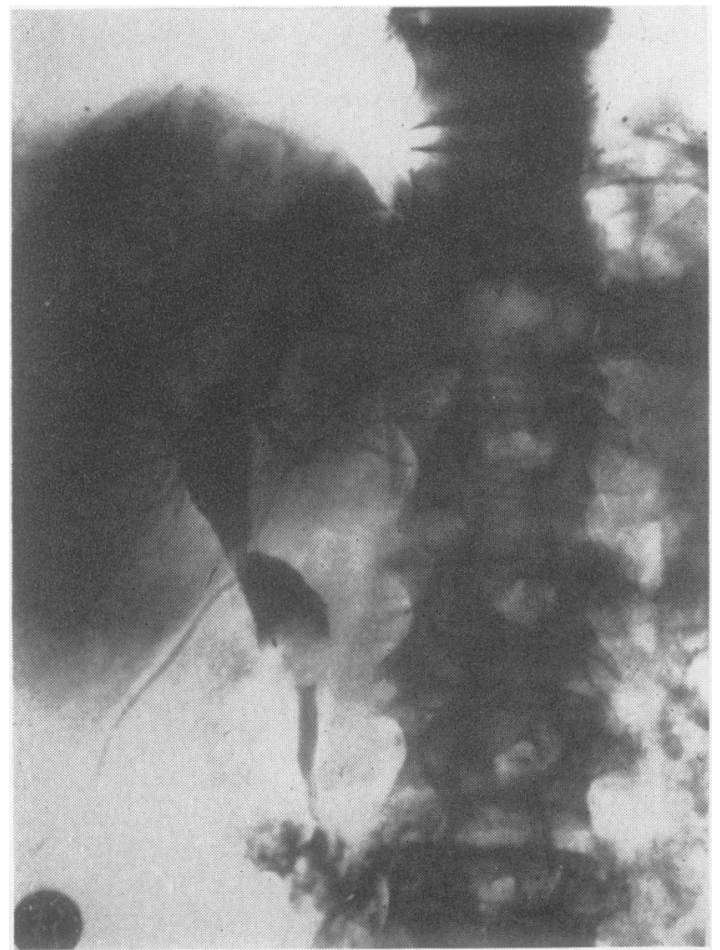

FIG. 3

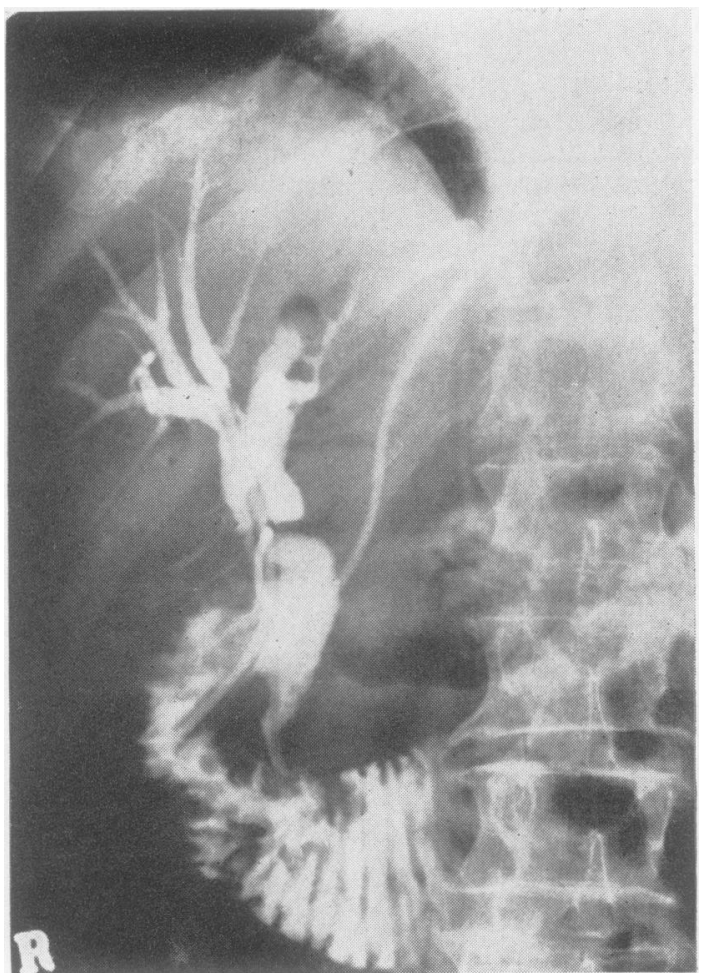

FIG. 5

FIG. 3. Case 1: Post-operative cholangiogram after the first operation showing a large filling defect at the lower end of the common bile duct. Note also that the narrow segment of the lower common bile duct represented in Fig. 1 is quite long in this patient. (Reproduced by kind permission of the Editor, Archives of Surgery.)

FIG. 4. Case 1: A preliminary operative cholangiogram performed at the third operation showing the filling defect at the lower end of the common bile duct.

FIG. 5. Case 1: Post-operative T tube cholangiogram after the third operation. Note the false passage between the common bile duct and the duodenum with the long arm of the T tube going through it. 
then undertaken. At this operation a preliminary operative cholangiogram, performed before the common bile duct was opened, again showed the large filling defect at the lower end of the duct (Fig. 4). The common bile duct was dilated, but still no stone was palpated along its length. When the duct was explored no stone was found. The second part of the duodenum was then mobilized and opened. A urethral sound was passed down the common bile duct into the duodenum through what was thought to be the duodenal papilla. The duodenal opening was enlarged above the sound and a stone measuring $18 \mathrm{~mm}$. in diameter was removed from a shallow diverticulum of the lower end of the duct. A T tube was placed in the common bile duct with a long arm going through this newly created duodenal opening. A post-operative cholangiogram with the $T$ tube in position showed that the filling defect previously seen was no longer there. A false passage had been created between the common bile duct and the duodenum proximal to the duodenal papilla (Fig. 5).

After the third operation the patient had an uneventful convalescence and has had no further symptoms.

CASE 2 Mrs. M. S., a 69-year-old housewife, presented with a history of vomiting and abdominal pain as well as

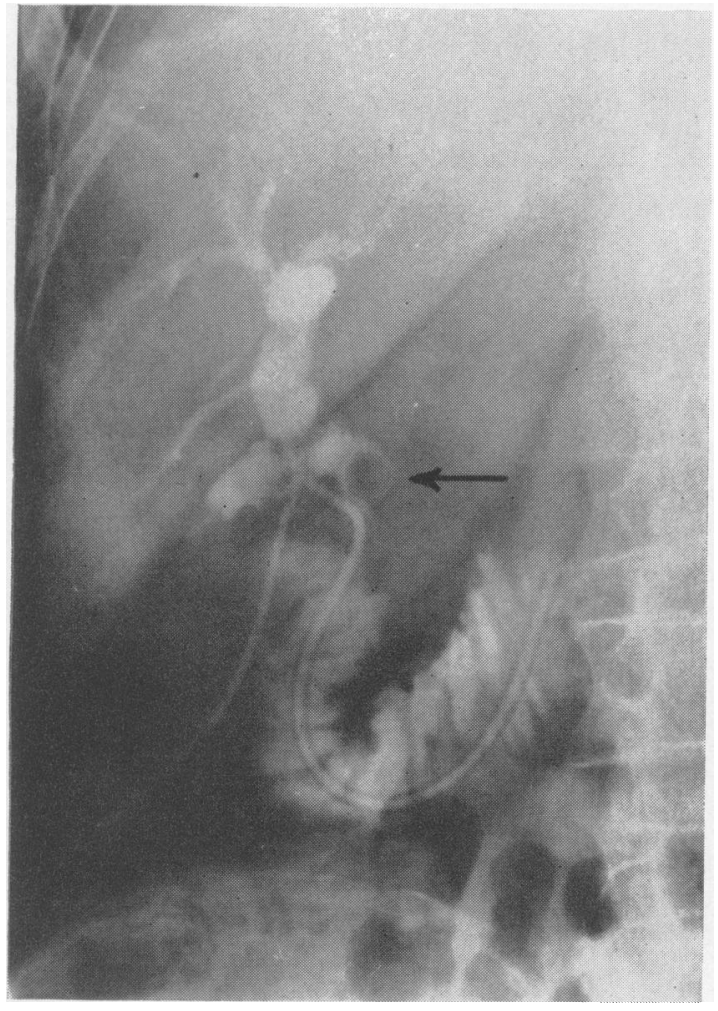

FIG. 6. Case 2: Post-operative T tube cholangiogram showing a large stone at the lower end of the common bile duct. obstructive jaundice for one week. She was an obese, jaundiced woman. There were no other physical findings. Liver function tests confirmed the obstructive nature of the jaundice. Radiographs of the gall bladder area revealed a number of opaque gall stones.

At operation the gall bladder was full of stones, and it was removed. The supraduodenal part of the common bile duct was dilated. The head of the pancreas, particularly around the lower end of the common bile duct, was indurated, but no stone was felt along the course of the duct. The common bile duct was opened and explored, but no stone was found. The duodenum was opened, and the common bile duct was explored from below but still no stone was found. A T tube was placed in the common bile duct with the long arm going through the duodenal papilla into the duodenum.

Post-operatively the patient's jaundice disappeared, and her general condition improved. However, a postoperative cholangiogram with the $T$ tube in position showed a calculus at the lower end of the common bile duct (Fig. 6).

As the patient refused further operative treatment, the $T$ tube was left in situ for eight months and then removed. A few days later she was readmitted to hospital with obstructive jaundice. At the second operation there was still a lot of induration around the lower end of the common bile duct. but a stone was not palpable. The common bile duct and the duodenum were both opened, and the duct explored from above and from below. After enlarging the opening of the duodenal papilla, a stone $12 \mathrm{~mm}$. in diameter was found in a diverticulum of the lower end of the common bile duct. Her post-operative cholangiogram with the $T$ tube in position was normal. She has had no further symptoms.

CASE 3 Mr. T. O'B., a 54-year-old labourer, presented with an 18-month history of biliary colic and a one-week history of biliary colic with obstructive jaundice, He was a jaundiced man with an enlarged, tender liver. There were no other physical findings. Investigations confirmed the obstructive nature of the jaundice.

At operation the gall bladder was tense and dilated, but contained no stones. The cystic duct and the common bile duct were dilated and thickened. No stones were felt along the course of the common bile duct. A preliminary operative cholangiogram showed dilatation of the common bile duct. Although no calculi were seen, no contrast entered the duodenum. Cholecystectomy was performed, and then the common bile duct was opened. Choledochoscopy was performed, and the surgeon was uncertain whether he could see a stone at the lower end of the common bile duct through the choledochoscope. Exploration of the duct was negative, but it was not possible to pass instruments through the duodenal papilla into the duodenum. The second part of the duodenum was mobilized and opened. The opening of the duodenal papilla was enlarged, and a large stone was removed from a diverticulum of the lower end of the common bile duct. The patient had an uneventful convalescence and has had no further symptoms. 
SUMMARY

Three cases presenting with obstructive jaundice are reported. At operation in each case a large gall stone was found to be lodged in a diverticulum of the lower end of the common bile duct. Two of the cases required further surgical intervention as the stone was overlooked at the initial operation. Operative cholangiography was a helpful diagnostic aid in all three cases. In every case transduodenal exploration of the common bile duct was necessary in order to remove the gall stone. One of the reasons at least why stones are overlooked during exploration of the common bile duct is that they are situated in diverticula of the duct.
I wish to thank Mr. Graham MacKenzie and Mr. Kenneth Cox for permission to publish two of the cases reported in this paper.

\section{REFERENCES}

Dowdy, G. S., Jr., Waldron, G. W., and Brown, W. G. (1962). Surgical anatomy of the pancreatobiliary ductal system. Arch. Surg., 84, 229-246.

Hand, B. H. (1963). An anatomical study of the choledochoduodenal area. Brit. J. Surg., 50, 486-494.

Hughes, E. S. R., and Kernutt, R. H. (1954). The terminal portion of the common bile duct and of the pancreatic duct of Wirsung. Aust. N.Z.J. Surg., 23, 223-235.

Kune, G. A. (1964). The surgical anatomy of the common bile duct. Arch. Surg., 89, 995-1004.

\section{The December 1964 Issue}

\section{THE DECEMBER 1964 ISSUE CONTAINS THE FOLLOWING PAPERS}

Crohn's disease of the large intestine H. E. LOCKHARTMUMMERY and B. C. MORSON

Histology of Crohn's syndrome w. JONES WILLIAMS

Ileo-caecal granulomata F. D. LEE and A. D. ROY

Ileo-caecal tuberculosis J. S. HOWELL, and P. J. KNAPTON

Distribution of histamine, 5-hydroxytryptamine, and other pharmacologically active substances in the human stomach J. G. MURRAY and J. H. WYLLIE

Mode of action of histamine in causing gastric secretion in man C. G. CLARK, V. JUNE CURNOW, J. G. MURRAY, F. O. STEPHENS, and J. H. WYLLIE

Gastric mucosal structure and function after vagotomy A. G. MELROSE, R. I. RUSSELL, and A. DICK

The gastric mucosa in radiologically negative acute gastrointestinal bleeding M. J. S. LANGMAN, J. H. HANSKY, R. A. B. DRURY, and F. AVERY JONES

Comparison of jejunal mucosa in post-gastrectomy states, idiopathic steatorrhoea, and controls using the dissecting microscope and conventional histological methods G. B. SCOTT, M. J. WILLIAMS, and C. G. CLARK

Leucine aminopeptidase in the pancreatic juice during ethionine pancreatitis KURT MÜLLER-WIELAND
Alterations of the enzyme output in ethionine pancreatitis KURT MÜLLER-WIELAND

Effect of acid in the duodenum on histamine-stimulated gastric secretion in man D. JOHNSTON and H. L. DUTHIE

Antacid therapy of peptic ulcer

Part I A mathematical definition of an adequate dose J. MYHILL and D. W. PIPER

Part II An evaluation of antacids in vitro D. W. PIPER and BARBARA H. FENTON

Perforated peptic ulcer in Israel S. LAZARUS

Local anaesthetics in the management of duodenal ulceration: A clinical trial of oxethazaine hydrochloride (Mucaine) ANTHONY H. GRABHAM

A trial of hypnosis in the management of recurrent mouth ulceration DEREK CHALMERS, and WILFRED SIRCUS

An assessment of the diagnostic and prognostic value of serum vitamin $\mathbf{B}_{\mathbf{1 2}}$ levels in liver disease C. D. HOLDSWORTH, MICHAEL ATKINSON, J. A. DOSSETT, and R. HALL

Effect of cholecystectomy on the role of the gall bladder in fat absorption A. KRONDL, H. VAV̌̌INKOVÁ, and č. MICHALEC

Index to volume 5

Copies are still available and may be obtained from the PUBLISHING MANAGER, BRITISH MEDICAL ASSOCIATION, TAVISTOCK SQUARE, W.C.I, price 18s. 6D. 